\title{
DSM-IV combined type ADHD Shows Familial Association with Sibling Trait Scores: A Sampling Strategy for QTL Linkage
}

Wai Chen, ${ }^{1}$ Kaixin Zhou, ${ }^{1}$ Pak Sham, ${ }^{1,2}$ Barbara Franke, ${ }^{3,4}$ Jonna Kuntsi, ${ }^{1}$ Desmond Campbell, ${ }^{1}$ Karin Fleischman, ${ }^{1}$ Jo Knight, ${ }^{1}$ Penny Andreou, ${ }^{1}$ Renée Arnold, ${ }^{5}$ Marieke Altink, ${ }^{3}$ Frits Boer, ${ }^{6}$ Mary Jane Boholst, ${ }^{1}$ Cathelijne Buschgens, ${ }^{3}$ Louise Butler, ${ }^{7}$ Hanna Christiansen, ${ }^{8}$ Ellen Fliers, ${ }^{3,9}$ Raoul Howe-Forbes, ${ }^{1}$ Isabel Gabriëls, ${ }^{10}$ Alexander Heise, ${ }^{11}$ Isabelle Korn-Lubetzki, ${ }^{12}$ Rafaela Marco, ${ }^{13}$ She'era Medad, ${ }^{14}$ Ruud Minderaa,15 Ueli C. Müller,16 Aisling Mulligan,7 Lamprini Psychogiou, ${ }^{17}$ Nanda Rommelse, ${ }^{18}$ Vaheshta Sethna, ${ }^{1}$ Henrik Uebel, ${ }^{11}$ Peter McGuffin, ${ }^{1}$ Robert Plomin, ${ }^{1}$ Tobias Banaschewski, ${ }^{11,19}$ Jan Buitelaar, ${ }^{3}$ Richard Ebstein, ${ }^{20}$ Jacques Eisenberg, ${ }^{20}$ Michael Gill, ${ }^{7}$ Iris Manor, ${ }^{14}$ Ana Miranda, ${ }^{13}$ Fernando Mulas, ${ }^{21}$ Robert D. Oades, ${ }^{8}$ Herbert Roeyers, ${ }^{10}$ Aribert Rothenberger, ${ }^{11}$ Joseph Sergeant, ${ }^{18}$ Edmund SonugaBarke, ${ }^{17}$ Hans-Christoph Steinhausen, ${ }^{16}$ Eric Taylor, ${ }^{1}$ Margaret Thompson, ${ }^{17}$ Stephen V. Faraone, ${ }^{22}$ and Philip Asherson ${ }^{1^{*}}$

\section{American Journal of Medical Genetics Part B 147B: 1450-1460}

This is the reformatted manuscript submitted - prior to publication in its final form at DOI 10.1002/ajmg.b.30672

1. MRC Social Genetic Developmental and Psychiatry Centre, Institute of Psychiatry, London, UK

2. Department of Psychiatry, LKS Faculty of Medicine, The University of Hong Kong, Pokfulam, Hong Kong

3. Department of Psychiatry, Radboud University Nijmegen Medical Center, Nijmegen, The Netherlands

4. Department of Human Genetics, Radboud University Nijmegen Medical Center, Nijmegen, The Netherlands

5. Center for Child and Adolescent Psychiatry, Triversum, Alkmaar, The Netherlands

6. Amsterdam Medical Centre - de Bascule, Amsterdam, The Netherlands

7. Neuropsychiatric Genetics Research Group, School of Medicine, Trinity College Dublin, Ireland

8. University Clinic for Child and Adolescent Psychiatry, Essen, Germany

9. BAVO-Europoort, Rotterdam, The Netherlands

10. Department of Experimental Clinical and Health Psychology, Ghent University, Belgium

11. Child and Adolescent Psychiatry, University of Göttingen, Germany

12. Shaare Zedek Medical Center, Jerusalem Israel

13. Department of Developmental and Educational Psychology, University of Valencia, Spain

14. ADHD Clinic, Geha Mental Health Center, Petach Tiqva, Israel

15. University Center of Child and Adolescence Psychiatry, University Medical Center, Groningen, The Netherlands

16. Department of Child and Adolescent Psychiatry, University of Zurich, Switzerland

17. School of Psychology, University of Southampton, Highfield, Southampton, UK

18. Department of Clinical Neuropsychology, VU University, Amsterdam, The Netherlands

19. Central Institute of Mental Health, Department of Child and Adolescent Psychiatry and Psychotherapy, Mannheim, Germany

20. S. Herzog Memorial Hospital, Jerusalem, Israel

21. Neuropediatric Service, University Hospital La Fe, Valencia, Spain 
22. Departments of Psychiatry and of Neuroscience \& Physiology, SUNY Upstate Medical University, Syracuse, NY, USA

Correspondence: *E-mail: p.asherson@iop.kcl.ac.uk

Grant sponsor: NIMH; Grant number: R01MH062873

\section{ABSTRACT:}

Attention deficit hyperactivity disorder (ADHD) is a discrete clinical syndrome characterized by the triad of inattention, hyperactivity, and impulsivity in the context of marked impairments. Molecular genetic studies have been successful in identifying genetic variants associated with ADHD, particularly with DSM-IV inattentive and combined subtypes. Quantitative trait locus (QTL) approaches to linkage and association mapping have yet to be widely used in ADHD research, although twin studies investigating individual differences suggest that genetic liability for ADHD is continuously distributed throughout the population, underscoring the applicability of quantitative dimensional approaches. To investigate the appropriateness of QTL approaches, we tested the familial association between 894 probands with a research diagnosis of DSM-IV ADHD combined type and continuous trait measures among 1,135 of their siblings unselected for phenotype. The sibling recurrence rate for ADHD combined subtype was $12.7 \%$, yielding a sibling recurrence risk ratio $\left(\lambda_{\text {sib }}\right)$ of 9.0. Estimated sibling correlations around $0.2-0.3$ are similar to those estimated from the analysis of fraternal twins in population twin samples. We further show that there are no threshold effects on the sibling risk for ADHD among the ADHD probands; and that both affected and unaffected siblings contributed to the association with ADHD trait scores. In conclusion, these data confirm the main requirement for QTL mapping of ADHD by demonstrating that narrowly defined DSM-IV combined type probands show familial association with dimensional ADHD symptom scores amongst their siblings.

KEY WoRDS: attention deficit hyperactivity disorder (ADHD); quantitative trait locus (QTL); linkage study; quantitative genetics; DF analysis

\section{INTRODUCTION:}

Attention deficit hyperactivity disorder (ADHD) is a common and heritable disorder that starts in early childhood and is characterized by developmentally inappropriate levels of hyperactive, impulsive, and inattentive behaviors accompanied by psychosocial impairments. The disorder is known to aggregate in families, with recent estimates suggesting a four to six-fold increase in the risk for ADHD among firstdegree relatives of $A D H D$ probands [Faraone et al., 2000; Brookes et al., 2006a]. Twin studies using parent and teacher rated ADHD symptom scales demonstrate the predominant role of genetic factors with heritability estimates in the range 60-90\% [Thapar et al., 1999;
Faraone et al., 2005]. Molecular genetic studies using candidate gene association approaches have yielded positive findings with dopamine and related monoamine neurotransmitter genes, in particular with genetic variants of the dopamine transporter, dopamine D4 and D5 receptor genes [reviewed in Asherson and The Image Consortium, 2004; Faraone et al., 2005; Brookes et al., 2006b; Li et al., 2006; Asherson et al., 2007]. Linkage studies using affected sib-pair or extended pedigree approaches have identified chromosomal regions containing putative risk alleles for ADHD [Fisher et al., 2002a; Bakker et al., 2003; Ogdie et al., 2003, 2004, 2006; Arcos-Burgos et al., 2004; Hebebrand et al., 2006].

In most cases association and linkage 
studies have used operational diagnostic criteria to define ADHD cases, or to classify affected pedigree members. Dichotomous classification of affection status is based on symptom checklist, pervasiveness, age of onset, and functional impairment criteria. In contrast to such all-or-none diagnostic categories, community cohorts, and twin samples have measured ADHD symptoms using dimensional symptom scales and demonstrated individual differences as continuously distributed quantitative traits. These studies suggest that genetic risk factors for ADHD also influence levels of ADHD symptoms through-out the population, implicating the existence of quantitative trait loci (QTLs) [see Stevenson et al., 2005]. QTLs refer genetic loci that contribute to quantitative individual differences. If proven, applying quantitative trait loci (QTL) approaches to genetic linkage and association studies would provide an alternative strategy to the use of diagnosed cases alone, with a potential gain in statistical power [Sham, 2002].

The key issue in determining whether QTL approaches are applicable to ADHD hinges upon the question of whether ADHD cases represent the extreme of the continuous distribution of ADHD symptoms scores in the population. An analogy is hypertension where those with high blood pressure represent the extreme of a continuously distributed trait.

This article argues that previous evidence supporting the use of QTL approaches for the genetic investigation of ADHD has been mainly inferential, since population twin samples have not applied operational diagnostic criteria to define "caseness" and have relied on continuous measures using rating scale data. We address this by using a sample of probands fulfilling research diagnostic criteria for combined type ADHD (ADHD-CT) and by investigating the association of $A D H D$ symptom scores among their siblings, thereby bridging the gap between the "discrete disorder" and "quantitative dimension" paradigms.

\section{Evidence from Clinical Samples, Community Cohorts, and Twin Data:}

There are 3 different phenotypic models, which could affect the application of QTL approaches: (i) discrete all-or none clinical syndrome (Model 1); (ii) discrete threshold effect (Model 2); and (iii) quantitative variability in the entire population (Model 3). Model 1 is analogous to Down syndrome [MIM 190685] in causing mental retardation, where it is self-evident that chromosomal abnormalities do not significantly contribute to the genetic variation of cognitive ability in the general population. Model 2 is analogous to the findings from a study on Specific Language Impairment (SLI) [Dale et al., 1998]. Genetic factors were found to account for $25 \%$ of the variance in vocabulary abilities across the entire distribution of the twin sample. However, DeFries and Fulker (DF) extremes analysis of the bottom $5 \%$ of the same sample revealed a group heritability estimate of about $73 \%$. The implication of this finding is that genetic influences acting on the extreme phenotype may not play any role in influencing individual differences within the normal range of language development [Fisher, 2002b]. A QTL approach applied to the normal range of language development is unlikely to detect genes responsible for SLI, which represents a qualitatively distinct extreme group demarcated by a specific threshold. Model I implies a "genetic syndromal entity" effect, whereas Model 2 indicates a "discrete threshold" effect. Both render QTL approaches inappropriate.

Several lines of published evidence suggest that ADHD symptoms do indeed represent quantitative variability throughout the entire population (i.e., Model 3). 
First, population twin studies have found similar high estimates of heritability using categorical diagnoses [Sherman et al., 1997a] and quantitative rating scale measures of ADHD symptoms [Edelbrock, 1986; Biederman et al., 1993; Chen et al., 1994; Boyle et al., 1997; Sherman et al., 1997b]. Second, nearly all twin data have defined ADHD dimensionally in terms of symptom scores [Thapar et al., 2006] and have shown that the genetic contribution to ADHD operates across the continuum and exerts a similar influence to those acting on individuals with extreme ADHD scores [Levy et al., 1997]. Third, putative environmental risk factors and prediction of adverse outcomes in epidemiological cohorts demonstrates a dose-response relationship with dimensional ADHD symptoms scores. For example, maternal smoking in pregnancy is associated with ADHD and also influences levels of ADHD symptoms throughout the population [Thapar et al., 2003]. Longitudinal studies based on community cohort samples have also reported association between antisocial behavior and maladjustment across ADHD severity scores [Wallander, 1988; Farrington et al., 1990; Fergusson and Horwood, 1995; Taylor et al., 1996]. In longitudinal follow-up studies, the adverse outcomes predicted by dimensionally defined "severity" were similar to those predicted by clinically defined "ADHD cases" [reviewed in Chen and Taylor, 2005]. Thus disparate strands of evidence converge to suggest that ADHD represents the extreme of a quantitative trait in the population.

The most direct test of the QTL model for ADHD is the multiple regression twin method proposed by De Fries and Fulker (DF). DF-analysis estimates group heritability from the differential regression of to the population mean of trait scores in the co-twins of monozygotic (MZ) and dizygotic (DZ) co-twin pairs; where the twin probands are selected for extreme scores [DeFries and Fulker, 1985, 1988]. Twin studies using this approach found similar heritability estimates for ADHD traits to those derived by univariate analysis of individual difference even when different thresholds were applied to define the proband group [Gillis et al., 1992; Stevenson, 1992; Gjone et al., 1996; Levy et al., 1997; Price et al., 2001]. For example, Price et al. [2001] in a population twin study of 6,000 pre-school twins found individual differences heritability ranging from 0.79 to 0.83 ; and group heritability estimates for the most hyperactive $5 \%$, $10 \%$, and $27 \%$ ranged from 0.83 to 0.93 . In another study, Gjone et al. [1996] investigated whether the heritability of attention problems increased with their severity. If cases at the extreme end of the dimension represent a discrete disorder and if recurrence of discrete ADHD cases in cotwins accounts for the heritability of attention and hyperactivity/impulsivity problems, then we would expect to see estimates of heritability change with changes in the severity threshold. However, heritability did not change with severity. The authors therefore concluded that there was in the population a continuously distributed dimension of genetic liability to attention problems. Similarly, in a community twin sample with learning difficulties, extreme inattention and hyperactivity/impulsivity scores were found to be attributable to genetic influences across varying diagnostic cut-offs [Willcutt et al., 2000]. Other authors reached similar conclusions [reviewed in Willcutt, in press; Stevenson et al., 2005]. Data derived from DF analyses of twin samples therefore provide more precise evidence that there is no demonstrable threshold effect demarcating extreme groups.

\section{Differences between Clinical Samples and Twin Data:}

Clinical samples used in most molecular 
genetic studies of ADHD have differed from twin studies in four important ways. First, most twins are ascertained from non-referred community populations; whereas "disorder" cases are recruited from specialist clinics and are thus subjected to referral and ascertainment biases, that is, referred cases are typically more severe and more likely to have comorbid conditions compared with nonreferred cases. Second, the prevalence of such clinical cases is relatively low, around $1.5-5 \%$ in the general population, while most DF twin analyses typically utilized top 5-30\% cut-offs to define extreme probands. The "extreme group" in twin samples thus contains milder or subthreshold cases which would not meet syndromal criteria and dilute the power to detect "discrete effects." Furthermore, published community twin studies have sample sizes ranging from about 200 pairs to 2000 pairs. Assuming a population prevalence of ADHD of $5 \%$, a typical twin sample would yield between 10 and 100 cases. Thus smaller twin samples are unlikely to contain sufficient ADHD cases for meaningful analysis. Among the larger community twin cohorts with sample sizes in thousands there were none that used operational diagnostic criteria and goldstandard diagnostic instruments.

Third, twin studies of ADHD have not included the age of onset, pervasiveness, or impairment criteria used in diagnostic definitions. Indeed, Canino et al. [2004] found important differences in prevalence dependent on inclusion of impairment as a diagnostic criterion. A survey in Newcastle found that prevalence was $11 \%$ for the syndrome with no impairment, $6.7 \%$ when associated with moderately low impairment, $4.2 \%$ for moderate impairment, and $1.4 \%$ for severe pervasive impairment [McArdle et al., 2004]. Embodied in the taxonomy of clinical syndromes is the "gestalt" paradigm. It is the unique constellation of several co- occurring cardinal features that characterizes a clinical syndrome, rather than one-dimensional additive scores. Thus, syndromal cases of ADHD ascertained by stringent methods and narrow definitions may represent an etiologically distinct entity.

Fourth, in diagnostic studies, ADHD cases are usually diagnosed using investigator-based or structured interviews performed by trained assessors following strict protocols. Such interview methods can minimize the influence of reporter bias. On the other hand, ADHD dimensional scores in twin studies are completed by untrained reporters using simple rating scale measures, and as a consequence are more prone to misinformation and misclassification.

Evidence in support of QTL approaches for the genetic study of ADHD has so far been inferred from indirect evidence derived from community twin data. It is however inferential in so far as there hitherto lacks direct empirical evidence, which can bridge the "discrete disorder" and "quantitative dimension" paradigms.

Here we report on familial correlations for ADHD symptom scores in a set of 894 families from the International Multicenter ADHD Gene project (IMAGE), which includes a methodological design encompassing the above two paradigms. We test for evidence of an overall shift in the distribution of ADHD symptoms in siblings related to ADHD clinical cases defined by diagnostic interviews. We test the hypothesis that siblings of ADHD probands will show similar sibling correlations to those reported in dizygotic twins from population samples. We also test whether an overall shift in mean scores is influenced by recurrence of discrete ADHD cases in the siblings.

\section{SUBJECTS AND METHOdS:}

\section{Subjects}


The IMAGE project is an international collaborative study that aims to identify genes, which increase the risk for ADHD using a combination of affected case and QTL linkage and association strategies. Subjects were recruited from 12 specialist clinics in 8 European countries: Belgium, Germany, Holland, Ireland, Israel, Spain, Switzerland, and United Kingdom. Both probands and siblings were required to be between the ages of 5-17, IQ_70, of European Caucasian descent and have access to at least one biological parent willing to provide DNA. Entry criteria for the probands are a clinical diagnosis of DSM-IV "combined subtype" of ADHD (ADHD-CT) and having one or more full siblings aged 5-17 available for ascertainment of clinical information and DNA collection. Exclusion criteria applying to both probands and siblings include autism, epilepsy, general learning difficulties, brain disorders and any genetic or medical disorder associated with externalizing behaviors that might mimic ADHD.

Both existing and de novo diagnosed patients were recruited following clinical evaluations by a pediatrician or child psychiatrist in the recent past. Wherever possible, families withdraw stimulant medication for one week prior to research assessment to allow for more accurate ascertainment of information on recent ADHD symptom characteristics and severity. Alternatively, we ensure as far as possible that ratings are based on medication free periods. Probands were excluded from the study if the last medication free period was more than 2 years ago or if they did not reach current DSM-IV criteria of ADHD-CT.

\section{Clinical Measures - Parental account of childhood symptoms, PACS.}

The PACS interview was conducted with the parents of probands with a clinical diagnosis of ADHD as well as siblings who were thought on the basis of parents descriptions of behavior to have ADHD. PACS is a semi-structured, standardized, investigator-based interview developed as an instrument to provide an objective measure of children's behavior [Taylor et al., 1986a,b, 1987; Chen and Taylor, 2006]. A trained interviewer administered PACS with parents, who were asked to for detailed descriptions of the child's typical behavior in a range of specified situations. Such situations were defined either by external events (e.g., watching television, reading a book or comic, playing alone, playing with friends, traveling, family outings, shopping trips, parental report of school problems) or by behaviors shown (e.g., crying, worries, tempers, fighting with siblings). Interviewers then made their own ratings, on the basis of a formal training and written definitions of the behaviors to be rated, on a 4-point scale of severity and frequency in the previous week and previous year. Inter-rater reliability was high with product-moment correlations for pairs of interviewers ranging from 0.79 to 0.96 [Taylor et al., 1986a]. PACS includes several subscales. Hyperactivity: this subscale is made up of attention span (time spent on a single activity, rated separately for four different kinds of activity), restlessness (moving about during the same activities), fidgetiness (movements of parts of the body during the same activities), and activity level (rated for structured situations such as mealtimes). Defiance: this subscale is composed of items concerning temper tantrums, lying, stealing, defiance, disobedience, truancy, and destructiveness. Emotional Disorder: this subscale is made up of items of misery, worrying, fears, and somatic symptoms that describe overt emotional stress rather than inferences concerning the emotional basis of symptoms. Comorbid and other problems: this section elicits symptoms of 
autistic spectrum disorders, attachment disorders, manic episode, substance abuse, psychotic symptoms, obsessivecompulsive symptoms, and other specific developmental disorder and neurological conditions.

All interviewers of the IMAGE project from each site attended a 5-day PACS training course in the UK. Each site further nominated a chief investigator who attended annual inter-rater reliability exercises. For sites with more than one interviewer, the local chief investigator undertook further inter-rater reliability checks regularly. A mean kappa coefficient across all the sites of 0.88 (range $0.71-$ 1.00) and an average agreement percentage of $96.6 \%$ (range 78.6-100) were obtained indicating a substantial level of inter-rater agreement. Concurrent validity of PACS diagnosis is confirmed by the point-biserial correlation between PACS diagnosis of ADHD-CT with Conners Teacher N-scale (18 DSM-items) scores at 0.68 and with Conners' Parent $\mathrm{N}$-scale scores at 0.78 .

\section{Rating scales}

Rating scales measures were applied to both ADHD cases and their unaffected siblings. These included the Long Version of Conners' Parent Rating Scale (CPRS-R:L), Long Version of Conners' Teacher Rating Scale (CTRS-R:L) [Conners, 2003], parent version of the Strengths and Difficulties Questionnaires (SDQ) and teacher version of the SDQ [Goodman, 1997; Rothenberger and Woerner, 2004]. The Hyperactivity scale of the SDQ consists of five items. The $\mathrm{N}$-subscale of CPRS and CTRS consists of 18 items compatible with the DSM-IV ADHD checklist of 18 diagnostic criteria. The $\mathrm{N}$-score is the summary score of two subscales $\mathrm{L}$ (inattentive - 9 items) and M (hyperactiveimpulsive - 9 items). Missing data in Conners' $L$ and $M$ subscales were prorated separately if seven or more items were present (i.e., more than $75 \%$ completion for each of the $L$ and $M$ subscales). This preserved independence of these two factors when pro-rating Conners' Scales for missing items.

For both the CPRS and CTRS the summary $\mathrm{N}$-scores were transformed into T-scores by mapping raw scores on the appropriate CPRS-R profile forms [Conners, 2003]. Conners T-scores are standardized for gender and age groups with the same mean (i.e., 50) and standard deviation (i.e., 10) for each subgroup based on tables of normative data. For example, a 6-year-old male with a raw score of 33 in the $\mathrm{N}$-subscale of the CPRS yields the same T-score of 70 as a 16-year-old male with a raw score 24 and a 16-year-old female with a raw score of 19. For the SDQ Hyperactivity scale we carried out a comparable procedure by obtaining age and gender standardized profile tables for T-scores transformation from Professor Robert Goodman [personal communication].

In order to exclude autism spectrum disorders that might confound the analysis of ADHD, both probands and siblings were screened using the Social Communication Questionnaire [Eaves et al., 2006] ( $\geq 15)$ in conjunction with the pro-social scale from the SDQ ( $\leq 4)$. Cases falling outside these thresholds were further evaluated using the autism spectrum disorder section of the PACS interview.

\section{Cognitive ability}

Both probands and siblings were screened for global learning difficulties with pro-rated full IQ scores derived from four subtests of the Wechsler Intelligence Scale for children [Children WISC-IIIUK; Wechsler, 1991]: picture completion, block design, similarities, and vocabulary. Individuals with pro-rated IQ lower than 70 were excluded from this analysis.

\section{DSM-IV diagnoses}


All raw data within the IMAGE project was centralized and stored on a database at the London site. An algorithm was used to derive each of the DSM-IV ADHD symptoms from the PACS interview data and these were combined with items that scored 2 or more from teacher ratings of DSM-IV items taken from the Connors rating scale. The diagnosis of ADHD was made if sufficient items were identified to fulfill DSM-IV criteria, and both impairment (based on severity of symptoms identified in the PACS interview) and pervasiveness (based on the presence of ADHD symptoms in more than one setting from PACS and scoring one or more items on the teacher Connors) were present. Since low teacher ratings for ADHD probands can occur when children are stably maintained on medication at school, situational pervasiveness outside the home setting is also captured in the PACS interview. In 28 cases where no Conners data was present pervasiveness was defined on the basis of PACS data alone.

Statistical Method:

\section{Calculating Group Familial Correlations ( $\mathrm{rg}$ )}

CPRS, CTRS, and SDQ T-scores were used to estimate the group familial correlations ( $\mathrm{rg}$ ) between trait liability and the clinical disorder using a method modified from DeFries-Fulker regression analysis [Purcell and Sham, 2003]: $\mathrm{rg}=$ (sibling mean - population mean)/ (proband mean - population mean). Data transformation and analyses were carried out using STATA 8 [2003]. The rg statistic provides an estimate of the sibling correlations and is comparable to sibling correlations derived from population samples. Given both Conners' and SDQ are standardized using community samples with a mean of 50 , we used a T-score of 50 as the population mean. The Conners' scores are standardized using a North American Caucasian population and
Conner reported that "when age and sex were taken into account, there were no differences between ethnic groups, or the differences were very small in magnitude" [Conners, 2003].

To guard against the possibility that the control data from North America does not match our European sample, we carried out further analysis using control data from a UK population twin sample [Martin et al., 2002]. The raw scores for 232 pairs of DZ twin pairs were transformed into Tscores according to the Conners' standardization tables. We then tested the hypothesis that means derived from the total ADHD symptom scale for twin 1 and twin 2 would be close to 50 if the Conners' standardization tables were applicable to the UK population. The tested means for teachers' Conners' were $50.33(95 \% \mathrm{Cl}=$ 49.26-51.41) for twin 1 and $50.88(95 \% \mathrm{Cl}$ $=49.26-51.41)$ for twin 2 .

The confidence intervals for the group sibling correlations ( $\mathrm{rg}$ ), as a quotient of two random variables, were calculated using the following equations [Mood et al., 1974]:

$$
\begin{aligned}
& E(X / Y)=Q(1+R(Y)-C(X, T) \\
& \operatorname{Var}(X / Y)=Q^{2}(R(X)+R(Y)-2 C(X, Y)
\end{aligned}
$$

where $X=$ means of siblings' scores, $Y=$ means of probands' scores, $Q=E(X) / E(Y)$, $R(X)=\operatorname{Var}(X) /(E(X))^{2}, R(Y)=\operatorname{Var}(Y) /(E(Y))^{2}$, $C(X, Y)=\operatorname{Cov}(X, Y) /(E(X) E(Y)), E(X)=\Sigma X_{i} / n$, $\operatorname{Var}(X)=\Sigma X_{i}^{2}-(E(X))^{2}, E(Y)=\Sigma Y_{i} / n, \operatorname{Var}(Y)$ $\left.=\Sigma Y_{i}^{2}-(E(Y))^{2}, \operatorname{Cov}(X, Y)=\Sigma X_{i}-E(X) E(Y)\right)$.

\section{RESULTS:}

\section{Sample and Measures}

The dataset used in this analysis consisted of 894 probands with DSM-IV ADHD combined subtype diagnosis and 1,135 of their siblings unselected for phenotype. Eighty-seven percent of the ADHD probands were male, compared to $52 \%$ of the siblings. The age range for both probands and siblings was between 5 and 
17 years, with the mean age of 10.9 (SD $1 / 42.7)$ for probands and $10.9(S D=3.3)$ for siblings.

For prorating Conners' scales, 675 of 894 (75.5\%) families returned fully completed parent and teacher Conners' for both children. Of the remaining families, 193 (21.6\%) had one of the 4 subscales prorated, $17(1.90 \%)$ had two of the 4 sub-scales prorated and $9(1.0 \%)$ had 3 or 4 prorated. Families having any missing data in the hyperactivity scale of the SDQ or having $25 \%$ or more missing data in Conners' subscales were excluded from this analysis. Fifty-six subjects were excluded, yielding 894 probands and 1,135 siblings with complete data used in this analysis.

\section{Sibling Concordance for DSM-IV ADHD Combined Subtype}

We identified 103 male siblings and 41 female siblings who fulfilled the same strict research criteria for ADHD-CT as the probands. This gave an overall sibling recurrence rate of $12.7 \%(144 / 1,135)$ (95\% $\mathrm{Cl}: 10.8-14.7)$. When compared to recent estimates of the population prevalence in the UK using similar criteria for ADHD-CT [Ford et al., 2003], this generated an overall sibling recurrence risk ratio $\left(\lambda_{\text {sib }}\right)$ for the ADHD-CT of 9.0 (12.7/1.41) (95\% $\mathrm{Cl}$ : 7.7-10.4).

We then tested for the effect of proband severity on sibling recurrence rate, by sub-fractionating the probands into quintile groups according to severity based on the average of the standardized ADHD scores across the four subscales. We computed the rates of ADHD-CT in siblings related to the 5 strata of probands. The sibling recurrence rates were $13.4 \%$ (95\% Cl: 9.5-18.2), 8.4\% (95\% $\mathrm{Cl}: 5.1-13.0), 11.6 \%$ (95\% Cl: 7.7-16.7), $16.8 \%$ (95\% Cl: $12.2-22.3)$, and $12.7 \%$ $(95 \% \mathrm{Cl}: 8.6-17.7)$ with increasing severity in proband quintile groups. There was no significant difference between the groups $\left(\chi^{2}(4)=7.4226, P=0.115\right)$ and no evidence of an effect or a trend that proband severity affects concordance rates.

\section{( $\mathrm{rg})$}

Group Familial (sibling) Correlations

For parent rated CPRS $\mathrm{N}$-subscale scores (containing scores of 18 DSM-IV items), the proband mean was 77.1 (95\% $\mathrm{Cl}$ : 76.6-77.7) and the sibling mean was 55.6 (95\% Cl: 54.9-56.4). For teacher rated CTRS $\mathrm{N}$-subscale scores, the proband mean was 70.2 (95\% Cl: 69.5-70.9) and the sibling mean was 56.0 (95\% Cl: 55.356.7). Table I summarizes the estimated sibling correlations for the parent and teacher rated ADHD symptom scores from the SDQ and Conners' scales. Sibling correlations for the four scales examined in the IMAGE sample were comparable with those reported in community twin studies. With the exception of the parent rated SDQ, this indicates a shift in the mean ADHD scores from the population mean in the siblings of ADHD probands, consistent with a familial association between proband diagnosis and ADHD symptoms among their siblings.

We further tested whether the shifts in the overall means of the sibling population can be explained by the increased rate of ADHD cases among siblings, rather than a mean shift in the overall sibling distribution. Figure 1 shows four histograms illustrating the distribution of ADHD symptom scores amongst siblings and probands for the CPRS and CTRS ( $N$ subscales). Visual inspection of these plots shows no apparent discrete "humps" (representing discrete cases) indicating possible bimodality of the phenotypic data. A minority of probands has low rating while their behaviors were rated on medication.

In order to test for possible proband threshold effects on the familial association with sibling ADHD scores, we sub-classified the siblings into five groups 
TABLE 1. Group-Sibling Correlations (rg) with 95\% Confidence Intervals

IMAGE Study Results

Published Population

Twin Literature

\begin{tabular}{|c|c|c|c|c|}
\hline & $\begin{array}{l}\text { Group-sibling } \\
\text { Correlations (rg) }\end{array}$ & $95 \% \mathrm{CI}$ & P-value & $\begin{array}{l}\text { Weighted mean } \\
\text { of rDZ }\end{array}$ \\
\hline $\begin{array}{l}\text { Teacher Connors } \\
\text { (Long scales) }\end{array}$ & 0.30 & $0.22-0.37$ & $<0.001$ & 0.36 \\
\hline $\begin{array}{l}\text { Teacher SDQ } \\
\text { (Short scales) }\end{array}$ & 0.31 & $0.20-0.42$ & $<0.001$ & 0.28 \\
\hline $\begin{array}{l}\text { Parent Conners } \\
\text { (Long scales) }\end{array}$ & 0.21 & $0.16-0.25$ & $<0.001$ & 0.28 \\
\hline $\begin{array}{l}\text { Parent SDQ } \\
\text { (Short scales) }\end{array}$ & 0.03 & $-0.01-0.07$ & 0.148 & -0.03 \\
\hline
\end{tabular}

The rg statistic represents the familial correlation between DSM-IV subtype probands and ADHD symptoms scores among their siblings. The means weighted by sample size of DZ twin correlations (rDZ) estimated from published population twin data (Table 2) are listed for comparison. Studies are grouped into those using long scales ( $\geq 10$ items) and short scales ( $\leq 6$ items).
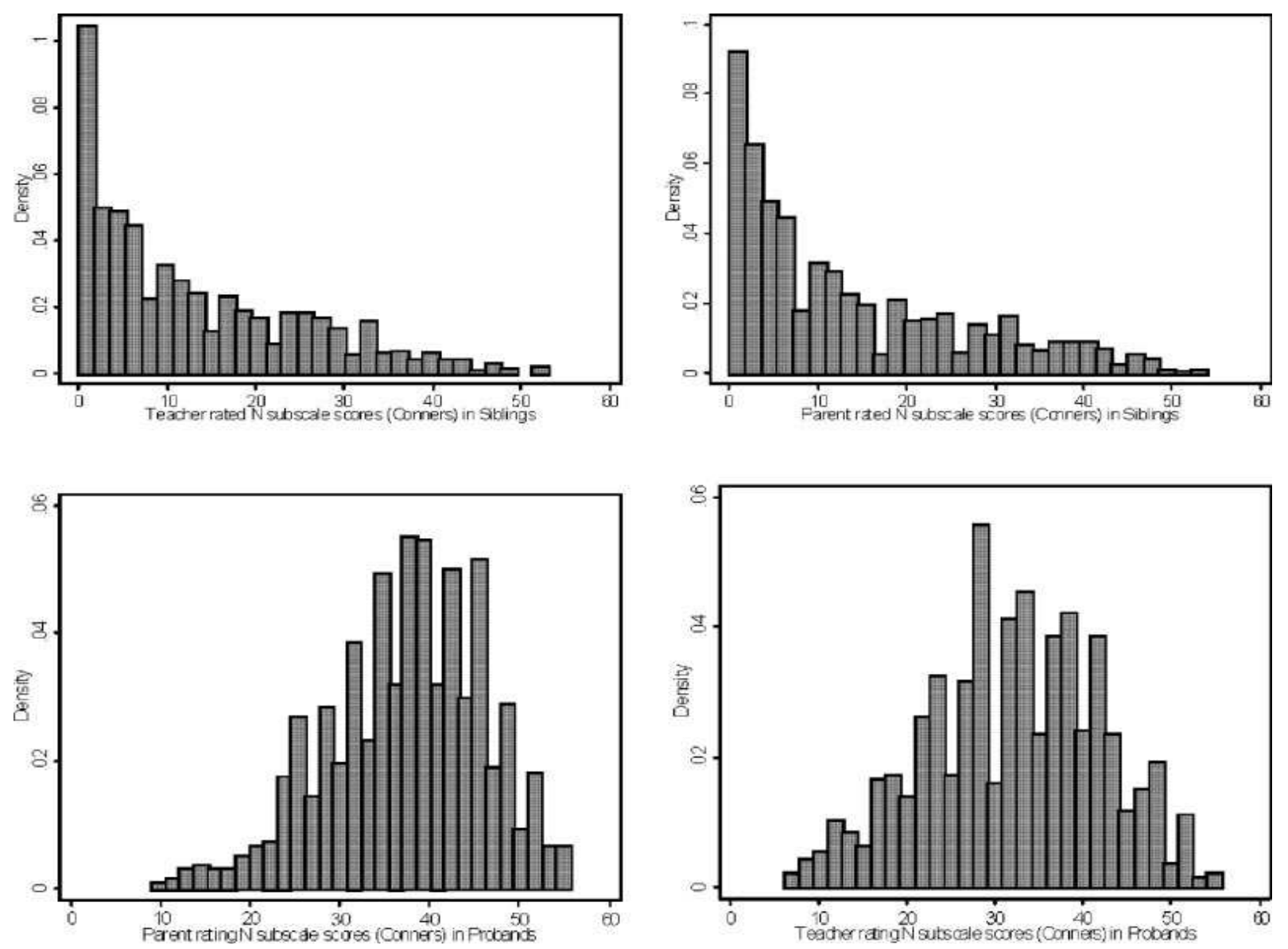

Figure 1. Histograms of teacher and parent rated $\mathrm{N}$-subscale from Conners scales for probands and siblings. The N-subscale includes 18 DSM-IV checklist items. 
according to the severity of their related probands. The probands were first subfractionated into quintile groups according to their severity based on the average of the standardized ADHD symptom scores for the four subscales, and their quintile status were then linked with their related siblings. Figure 2 shows the mean scores for the five subgroups of related siblings. We hypothesize that differences in siblings' means would be detected if familiality were mainly driven by more severe probands. The sibling subgroup means were estimated using regression methods rather than ANOVA because of unequal variances. Bartlett's tests for parent rated CPRS $\mathrm{N}$-subscale scores was significant $\left(\chi^{2}(4)=18.2, P=0.001 ; S D\right.$ were $12.5,12.2,12.8,15.3$, and 14.5 for siblings related to proband quintile groups of increasing severity). Ninety-five percent confidence intervals were thus estimated based on the sandwich or Huber/White variance estimator [Rogers, 1993; Williams, 2000] available in STATA 8 [2003], which is robust to violation of the equal variance assumption used in ANOVA. All 95\% confidence intervals overlap as shown in Figure 2 and no proband severity threshold effect or a trend of such effect could be detected.

We further tested whether the association between proband diagnosis and sibling ADHD scores could be explained by the increased recurrence rate for ADHD among siblings of ADHD probands. In Figure 2, the mean ADHD scores for the entire set of siblings (solid lines) within each proband subgroup are significantly different from the standardized population mean of 50 . When we removed ADHD cases from the sibling groups (dotted lines) the mean scores of the non-ADHD siblings remained significantly different from the population mean. The overall mean of the subsample of non-ADHD siblings was $53.1(95 \% \mathrm{Cl}$ : 52.3-53.8) for parents' CPRS scores (compared with 55.6 (95\% Cl: 54.9-56.4) for the entire sibling sample) and 54.3 (95\% Cl: 53.5-55.0) for teachers' CTRS scores (compared with 56.0 (95\% Cl: 55.356.7) for the entire sibling sample). This indicates that the shift in sibling scores for the population mean is not driven entirely by the increased sibling recurrence rate of $A D H D$, since the sibling means do not regress fully back to the population mean after the removal of sibling ADHD cases. This provides further support for the quantitative trait model of ADHD.
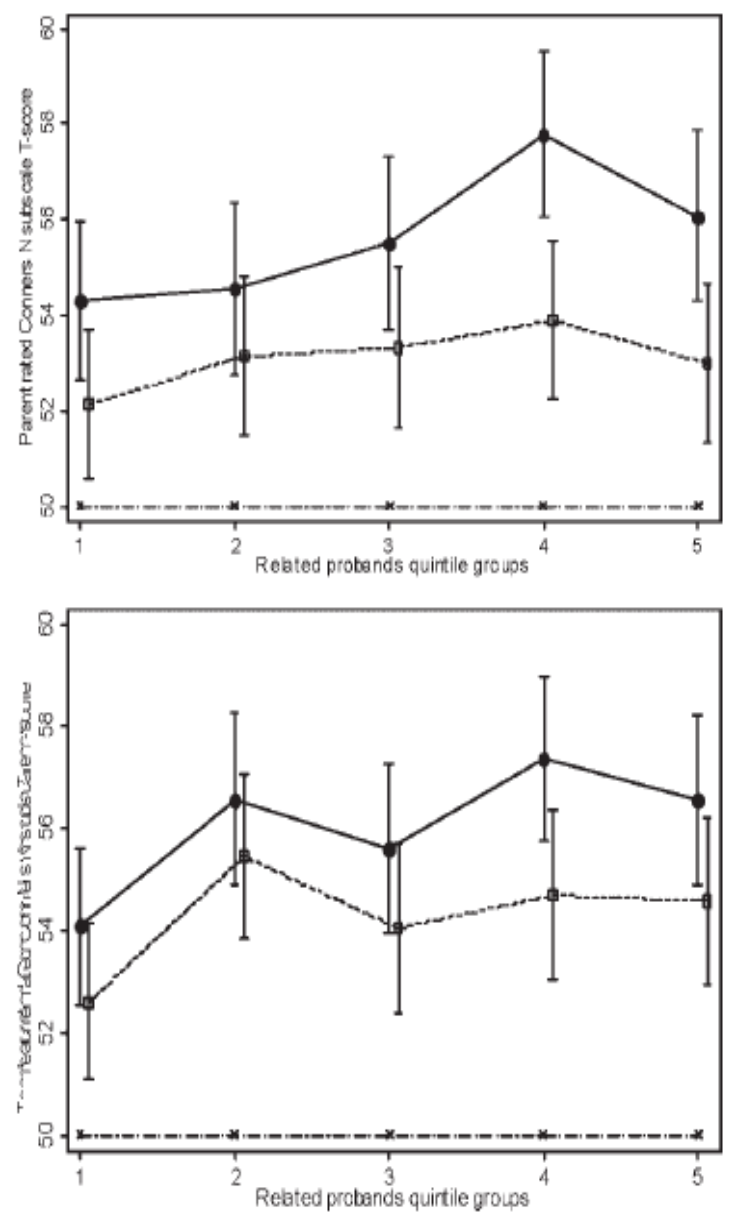

Figure 2. Means of parent and teacher rated Conners N-scores for sibling of ADHD probands. Related probands were grouped into quintile strata based on proband's ADHD symptom severity. Error bars represent 95\% confidence intervals. Significant differences in the means are seen between the population mean (dashed line) and the siblings' means, whether based on the entire set of siblings (filled line), or based on a subset on nonADHD siblings (dotted line). 


\section{Discussion:}

There are four key findings in this study. First we replicated previous findings of increased recurrence risk of ADHD-CT in siblings of ADHD-CT probands. Second, our results demonstrated an overall shift in the distribution of dimensional ADHD symptom scores from population means among the siblings of ADHD-CT probands. This indicates that there is a familial association between the discrete category of ADHD-CT cases (represented by the probands) and the continuous dimension of ADHD symptom ratings (represented by their siblings). The estimated sibling correlations from this study were very similar to those derived from the analysis of fraternal twins in population twin data. Third, inspection of the proband and sibling ADHD distributions showed no apparent bimodality, which would have suggested a discrete disorder rather than a continuous trait. Finally, we specifically tested for discrete threshold effects by sub-classifying siblings according to severity of ADHD scores among their related probands. There was no evidence of threshold effects based upon proband severity, influencing either the recurrence rates of ADHD cases among siblings or dimensional ADHD scores. Even when ADHD cases were removed from the sibling group, a distributional shift in ADHD symptoms from the population mean still remained among the unaffected ADHD siblings. The overall shift in the mean ADHD score for siblings of DSM-IVCT probands could therefore not be explained only by the increased concordance rate of the clinical disorder among siblings. Therefore, our findings show no evidence for a discrete process that demarcates ADHD from quantitative traits.

The sibling relative risk ratio $\left(\lambda_{\text {sib }}\right)$ for ADHD-CT identified in this study is higher than previous estimates for broad ADHD
[Faraone et al., 2000]. This may suggest that application of strict operational criteria to the selection of DSM-IV ADHDCT probands defines a more familial clinical group, perhaps with greater genetic loading. The $\lambda_{\text {sib }}$-values are the ratio of the prevalence among siblings to that in population controls and therefore tend to be lower for more common disorders. The previous estimate for broad ADHD used an estimated sibling recurrence rate of $20.0 \%$ while the control rate used was 5.0\% [Faraone et al., 2000], yielding a $\lambda_{\text {sib }}$ of 4.0 ; whereas our sibling recurrence rate for ADHD-combined type was $12.7 \%$ and the control rate used was $1.41 \%$, yielding a $\lambda_{\text {sib }}$ of 9.0 . Since we did not include a control sample in this study, we can only estimate the population prevalence from a large epidemiological study in the UK [Ford et al., 2003]. As a result, the $\lambda_{\text {sib }}$ estimates in this study can only be taken as an approximate guide.

While a familial association between "ADHD syndrome" and "ADHD symptom scores" among siblings may appear to be self-evident by inference from the preceding literature, there is in fact little data that provides a direct empirical evaluation of this. Indeed uncertainty over the possible links between the clinical disorder and normal variation of ADHD scores in the general population has recently been raised [Thapar et al., 2006] and some alternative models such as genetically distinct latent classes have been suggested [Todd et al., 2001]. Our findings therefore provide direct empirical evidence which bridge the gap in published literature.

The data presented here address two main methodological limitations of previous twin studies. First, when considering the applicability of QTL approaches to genetic studies of ADHD it is important to provide empirical confirmation of the core assumption, that 
genetic influences on ADHD are not restricted to an increased rate of clinical cases among siblings (i.e., increased case concordance). There would need to be an overall shift in the distribution of sibling ADHD symptoms similar to that seen in population twin samples. This confirmation can only be provided by datasets with two distinct design features: (1) dual ascertainment of clinical cases and related affected and unaffected siblings; and (2) dual information ascertainment of dimensional behavioral measures (from rating scales) and categorical classification (from gold-standard diagnostic interviews). The data presented in this study fulfil both conditions.

Previously, dual information from rating scales (by teachers) and from structured diagnostic interview (by parent) was simultaneously available in only one twin sample [Sherman et al., 1997a, b]. In the first report, twin concordance and tetrachoric correlations based on diagnostic categories derived from teacher and parent information were compared [Sherman et al., 1997a]. In the second analysis, dimensional factor scores derived from principal-components analysis were used. Though both categorical (structured interview derived) and dimensional (rating scale derived) data were available in this sample, the authors have not specifically tested for a bivariate relationship between these two sets of measures. Our data address this specific gap in the literature.

Second, published DF twin analyses typically utilized top 5-30\% cut-offs to define extreme probands, while the prevalence of syndromal ADHD cases is comparatively low. The "extreme group" in twin samples therefore usually contains milder or sub-threshold cases, who would not meet syndromal criteria and could thereby dilute the power to detect "discrete effects." In this study we applied a modified DF analysis to estimate the sibling correlation for parent and teacher ADHD rating scale scores, using a large sample of 894 narrowly defined DSM-IVCT probands and their siblings. The sample has adequate statistical power, comparable to larger twin samples. But the probands were ascertained from specialist clinics, and diagnosed based on strict protocol and operational diagnostic criteria. Siblings were not subject to any type of phenotypic selection beyond the major inclusion/exclusion criteria. The methodological design of our study therefore also addresses potential doubts over the applicability of broadly defined "extreme group" used in twin DF analyses to "ADHD syndrome" paradigm, thereby bridging both "discrete disorder" and "quantitative dimension" paradigms. The current dataset thus fulfils the main conditions required for an empirical evaluation of the QTL model.

The sibling correlations estimated in this study were very close to those fraternal twin correlations reported in population twin studies. In Table 2, we grouped the published twin studies into those that use short scales and those that use long scales and calculated the average DZ correlations weighted by sample size. Review of DZ correlations reported in the twin literature (as shown in Table 2) leads to several conclusions. First, that sibling correlations derived from teacher rated measures are on average slightly higher than those derived from parent rated measures. Second, there is greater variability amongst parent rated measures including a number of studies with near zero or negative correlations. Third, in most cases parent rated measures using long scales (i.e., DSM-IV checklists or similar rating scales) yield higher sibling correlations than those derived from short scales (i.e., Rutter A and SDQ). All studies using parent-rating scales with 6 or less items report near zero or negative DZ correlations, whereas this was not the 
case in twelve studies that used parent scales with 10 or more items. The reasons for low or negative DZ correlations from some parent rated scales has been discussed previously, it can be explained by parent rater contrast effects and possible dominance effects that appear to be far greater for short summary scales than more detailed symptom checklists [Eaves et al., 1997; Simonoff et al., 1998; Martin et al., 2002].

In line with these above observations, the estimated correlations from the current IMAGE study are consistent with the literature on DZ twin correlations across all four scales used (see Table 1). This finding provides additional support that a carefully defined clinical group fulfilling DSMIV criteria for ADHD-CT shows a similar pattern of sib-correlations to those derived from population samples. The resemblance of our data to those derived from twin studies is not merely on a global level, but also borne out on specific characteristics of different scales, such as higher correlation detected for the long teachers' rating scale and lower correlation for the short parents' rating scale.

Our conclusion on the basis of these data is that DSM-IV ADHD-CT is likely to represent the extreme of a continuously distributed trait found in the general population. These data provide empirical evidence that supports the inference from population twin data to ADHD cases. In so doing they provide an empirical justification for the use of QTL approaches for the detection of genes that influence the risk for ADHD.

Overall our findings indicate that QTL linkage is expected to be a suitable strategy for detecting ADHD liability genes of moderate to large effect. We estimate, for example, that a sample of 700 probands and their unselected siblings has 65-75\% power to detect a QTL accounting for $10 \%$ of the genetic variance and $30-$ $45 \%$ power for a $5 \%$ QTL. A larger sample of 1,400 families would have $87-98 \%$ power for a $10 \%$ QTL and $45-65 \%$ for a $5 \%$ QTL. The sampling strategy used in the IMAGE study is relatively easy to collect compared to an affected sibling pair strategy and further provides a powerful dataset for both categorical and quantitative trait approaches to association analysis. To date only a few ADHD studies have adopted QTL methods for association [Mill et al., 2005; Curran et al., 2005; Cornish et al., 2005] and this strategy still needs to be confirmed by actual findings of genes that increase risk for ADHD.

\section{LIMITATIONS:}

Limitations of this study include the focus on DSM-IV combined subtype probands. We could therefore not investigate the familial association of sibling trait scores for the other ADHD subtypes. Using a DF analysis approach Willcutt et al. [2001] showed that both inattentive and hyperactive-impulsive symptoms were highly heritable when probands were selected for either the combined or inattentive subtypes. However, the heritability of hyperactiveimpulsive symptoms was substantially lower and non-significant when probands were selected for the hyperactiveimpulsive subtype. Todd et al. [2001] in their analysis of a twin sample of adolescent females, found that while there was significant cross-concordance between combined and inattentive subtypes there was little crossconcordance between either of these and the hyperactive-impulsive subtype. In addition, using latent class analysis they found evidence that different latent subgroups, including groups separated on the basis of severity of symptoms, tend to breed true; perhaps reflecting the influence of different sets of genes on 
TABLE 2.

Summary Table of Published Dizygotic Twin Correlations (rDZ) from Population Twin Studies using Parent and Teacher Rating Scales

\section{$\underline{\text { References }}$}

Martin et al. [2002]

Thapar et al. [2000]

Coolidge et al. [2000]

Levy et al. [1997]

Sherman et al. [1997a, b]

Gjone et al. [1996]

Gjone et al. [1996]

Hudziak et al. [2003]

Rietveld et al. [2003]

Rietveld et al. [2003]

Rietveld et al. [2003]

Edelbrock et al. [1995]

Nadder et al. [1998]

Martin et al. [2002]

Kuntsi \& Stevenson [2001]

Thapar et al. [2000]

Thapar et al. [1995]

Goodman \& Stevenson [1989] Rutter A

\section{References}

Martin et al. [2002]

Kuntsi \& Stevenson [2001]

Sherman et al. [1997a, b]

Simonoff et al. [1998]

Nadder et al. [2002]

Thapar et al. [2000]

Martin et al. [2002]

Goodman \& Stevenson [1989] Rutter B

\section{Parent rated measure}

Conners' (10 items)

Du Paul (18 items)

CPNI (18 items)

BRS (14 items)

DICA (20 items)

CBCL (age 5-9)

CBCL (age 12-15)

CBCL

CBCL (age 7)

CBCL (age 10)

CBCL (age 12)

CBCL

Telephone interview (6 items)

SDQ

Conners' (4 items)

Rutter A

Rutter A

$\underline{\text { Teacher }} \underline{\text { rated measure }}$

Conners' (10 items)

Conner's (7 items)

Combined Conners'+ Rutter B 93

Combined Conners'+ Rutter B 501

Combined Conners'+ Rutter B 260

807

378

90 378

\section{$\underline{\mathrm{rDZ}}$}

0.25

0.32

0.18

0.49

0.31

$0.20 \mathrm{a}$

$0.40 \mathrm{a}$

0.23

$0.21 \mathrm{a}$

$0.26 \mathrm{a}$

$0.27 \mathrm{a}$

0.29

$-0.08$

$-0.04$

$-0.01$

$-0.01$

$0.02 \mathrm{a}$

$-0.08$

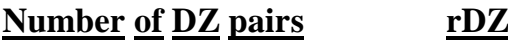

0.38

$0.37 \mathrm{~b}$

0.49

$0.26 \mathrm{c}$

0.30

0.42

0.29

0.26

a Average of rDZ cited separately for same-sex male, same-sex female and opposite sex twin pairs.

b Average of $\mathrm{rDZ}$ for hyperactive/impulsive and inattentive subscales.

c Average of rDZ for same and different teacher and same-sex male, same-sex female and opposite sex twin pair groups. 
different ADHD subgroups in the population. These findings appear to be robust since they replicated in a sample of Australian twins [Rasmussen et al., 2004] and appear to provide somewhat conflicting conclusions to those drawn from the analysis of ADHD as a quantitative trait. Finally, molecular genetic analysis of the dopamine D5 gene found that the association with ADHD was equally significant for both the combined and inattentive subtypes, but was not significant for a group of hyperactiveimpulsive probands [Lowe et al., 2004]. Given the limited resources, it was also not feasible to recruit a sufficiently large control group that can yield accurate prevalence rate for ADHD-CT. To ascertain accurately such a prevalence rate (around $1.5 \%)$ will involve surveying a sample of $10,000-80,000$ subjects across eight countries, which represent an undertaking beyond the scope of a genetic study. We therefore utilized estimates of population norms and population prevalence from existing data of published epidemiological samples. A low prevalence would inflate the estimated $\lambda_{\text {sib }}$, while a high prevalence rate will do the reverse.

\section{CONCLUSION:}

In conclusion, our analysis suggests that the IMAGE sample of probands and siblings, ascertained via DSM-IV combined subtype probands who were recruited from specialist ADHD clinics, can be used for QTL analysis. The familial correlations between DSM-IV ADHD-CT probands and sibling ADHD-trait scores are similar to those estimated from population studies using continuous rating scale data alone.

\section{REFERENCES:}

Arcos-Burgos $M$, Castellanos FX, Pineda D, Lopera F, Palacio JD, Palacio LG, Rapoport JL, Berg K, Bailey-Wilson JE, Muenke M. 2004. Attention deficit/ hyperactivity disorder in a population isolate: Linkage to loci at $4 q 13.2$, q33.3, 11q22, and 17p11. Am J Hum Genet 75:998-1014.

Asherson P, The IMAGE Consortium. 2004. Attention-Deficit Hyperactivity Disorder in the post-genomic era. Eur Child Adolesc Psychiatry 13(Suppl 1):50-70.

Asherson P, Brookes K, Franke B, Chen W, Gill M, Ebstein R, Buitelaar J, Banaschewski T, Sonuga-Barke $E$, Eisenberg J, Manor I, Miranda A, Oades RD, Roeyers $H$, Rothenberger $A$, Sergeant J, Steinhausen HC, Faraone SV. 2007. Confirmation that a specific haplotype of the dopamine transporter gene is associated with combined type ADHD. Am J Psychiatry 164(4):674-677.

Bakker SC, van der Meulen EM, Buitelaar JK, Sandkuijl LA, Pauls DL, Monsuur AJ, van't Slot R, Minderaa RB, Gunning WB, Pearson PL, Sinke RJ. 2003. A wholegenome scan in 164 Dutch sib pairs with attention-deficit/hyperactivity disorder: Suggestive evidence for linkage on chromosomes $7 p$ and 15q. Am J Hum Genet 72:1251-1260.

Biederman J, Faraone SV, Doyle A, Lehman BK, Kraus I, Perrin J, Tsuang MT. 1993. Convergence of the Child Behavior Checklist with structured interviewbased psychiatric diagnoses of ADHD children with and without comorbidity. J Child Psychol Psychiatry 34:12411251.

Boyle MH, Offord DR, Racine YA, Szatmari P, Sanford M, Fleming JE. 1997. Adequacy of interviews versus checklists for classifying childhood psychiatric disorder based on parent reports. Arch Gen Psychiatry 54:793799.

Brookes K, Xu X, Chen W, Zhou K, Neale B, Lowe $N$, Anney R, Franke B, Gill M, Ebstein R, Buitelaar J, Sham P, Campbell $D$, Knight J, Andreou P, Altink M, Arnold $R$, Boer $F$, Buschgens C, Butler L, Christiansen $\mathrm{H}$, Feldman L, Fleischman 
K, Fliers E, Howe-Forbes R, Goldfarb A, Heise A, Gabriëls I, Korn-Lubetzki I, Johansson L, Marco R, Medad S, Minderaa $R$, Mulas $F$, Müller $U$, Mulligan A, Rabin $K$, Rommelse $N$, Sethna V, Sorohan J, Uebel $H$, Psychogiou L, Weeks A, Barrett R, Craig I, Banaschewski T, Sonuga-Barke $E$, Eisenberg J, Kuntsi J, Manor I, McGuffin $P$, Miranda A, Oades RD, Plomin R, Roeyers $H$, Rothenberger A, Sergeant J, Steinhausen HC, Taylor E, Thompson M, Faraone SV, Asherson P. 2006a. The analysis of 51 genes in DSM-IV combined type attention deficit hyperactivity disorder: Association signals in DRD4, DAT1 and 16 other genes. Mol Psychiatry 11(10):934-953.

Brookes KJ, Mill J, Guindalini C, Curran S, $\mathrm{Xu} X$, Knight J, Chen CK, Huang YS, Sethna V, Taylor E, Chen W, Breen G, Asherson P. 2006b. A common haplotype of the dopamine transporter gene associated with attention deficit/ hyperactivity disorder and interacting with maternal use of alcohol during pregnancy. Arch Gen Psychiatry 631:74-81.

Canino G, Shrout PE, Rubio-Stipec M, Bird HR, Bravo M, Ramirez R, Chavez L, Alegria $M$, Bauermeister JJ, Hohmann A, Ribera J, Garcia P, Martinez-Taboas A. 2004. The DSM-IV rates of child and adolescent disorders in Puerto Rico: Prevalence, correlates, service use, and the effects of impairment. Arch Gen Psychiatry 61(1):85-93.

Chen W, Taylor E. 2005. Resilience, hyperactivity and impaired self-control. In: Goldstein S, Brooks R, editor. Handbook of Resilience in Children. New York: Kluwer. pp 257-278.

Chen W, Taylor E. 2006. PACS Interview and genetic research of ADHD. In: Oades RD, editor. Attentiondeficit/hyperactivity disorder ADHD and hyperkinetic syndrome HKS:
Current ideas and ways forward, 1 e. New York: Nova Science Publishers. pp 3-20.

Chen WJ, Faraone SV, Biederman J, Tsuang MT. 1994. Diagnostic accuracy of the child behavior checklist scales for attention deficit hyperactivity disorder: A receiver operating characteristic analysis. J Consult Clin Psychol 62:1017-1025.

Conners CK. 2003. Conners' Rating ScalesRevised: Technical Manual.

Sixth Printing, North Tonawanda, New York: Multi-Health System Inc.

Coolidge FL, Thede LL, Young SE. 2000. Heritability and the comorbidity of attention deficit hyperactivity disorder with behavioral disorders and executive function deficits: A preliminary investigation. Dev Neuropsychol 17:273-287.

Cornish KM, Manly T, Savage R, Swanson J, Morisano D, Butler N, Grant C, Cross G, Bentley L, Hollis CP. 2005. Association of the dopamine transporter (DAT1) 10/10-repeat genotype with ADHD symptoms and response inhibition in a general population sample. Mol Psychiatry 10(7):686-698.

Curran S, Purcell S, Craig I, Asherson P, Sham P. 2005. The serotonin transporter gene as a QTL for ADHD. Am J Med Genet Part B 134B (1):42-47.

Dale PS, Simonoff E, Bishop DV, Eley TC, Oliver B, Price TS, Purcell S,

Stevenson J, Plomin R. 1998. Genetic influence on language delay in two year-old children. Nat Neurosci 14:324328.

DeFries JC, Fulker DW. 1985. Multiple regression analysis of twin data. Behav Genet 15:467-473.

DeFries JC, Fulker DW. 1988. Multiple regression analysis of twin data: 
Etiology of deviant scores versus individual differences. Acta Genet Med Gemellol (Roma) 37:205-216.

Eaves LJ, Silberg JL, Meyer JM, Maes HH, Simonoff E, Pickles A, Rutter M, Neale MC, Reynolds CA, Erikson MT, Heath AC, Loeber R, Truett KR, Hewitt JK. 1997. Genetics and developmental psychopathology: 2 . The main effects of genes and environment on behavioral problems in the Virginia Twin Study of Adolescent Behavioral Development. J Child Psychol Psychiatry 38:965-980.

Eaves LC, Wingert H, Ho HH. 2006. Screening for autism: Agreement with diagnosis. Autism 10(3):229-242.

Edelbrock C. 1986. Behavioral ratings of children diagnosed for attention deficit disorder. Psychiatr Ann 16:36-40.

Edelbrock C, Rende R, Plomin R, Thompson LA. 1995. A twin study of competence and problem behavior in childhood and early adolescence. J Child Psychol Psychiatry 36:775-785.

Faraone SV, Biederman J, Monuteaux MC. 2000. Toward guidelines for pedigree selection in genetic studies of attention deficit hyperactivity disorder. Genet Epidemiol 18:1-16.

Faraone SV, Perlis RH, Doyle AE, Smoller JW, Goralnick JJ, Holmgren MA, Sklar P. 2005. Molecular genetics of attentiondeficit/hyperactivity disorder. Biol Psychiatry 57(11):1313-1323.

Farrington DP, Loeber R, van Kammen WB. 1990. Long-term criminal outcomes of hyperactivity-impulsivity-attention deficit and conduct problems in childhood. In: Robins L, Rutter $M$, editors. Straight and devious pathways from childhood and adulthood. Cambridge: Cambridge University Press. pp. 62-81.

Fergusson DM, Horwood LJ. 1995. Predictive validity of categorically and dimensionally scored measures of disruptive childhood behaviors. J Am Acad Child Adolesc Psychiatry 344:477485.

Fisher SE. 2002b. Isolation of the genetic factors underlying speech and language disorder. In: Plomin R, DeFries JC, Craig IW, McGuffin P, editors. Behavioural genetics in the postgenomic era, $1 \mathrm{e}$. Washington DC: American Psychological Association. pp 205-226.

Fisher SE, Francks C, McCracken JT, McGough JJ, Marlow AJ, MacPhie IL, Newbury DF, Crawford LR, Palmer CG, Woodward JA, Del'Homme M, Cantwell DP, Nelson SF, Monaco AP, Smalley SL. 2002a. A genome wide scan for loci involved in attention-deficit/ hyperactivity disorder. Am J Hum Genet 70:1183-1196.

Ford T, Goodman R, Meltzer H. 2003. The British Child and Adolescent Mental Health Survey 1999: The prevalence of DSM-IV disorders. J Am Acad Child Adolesc Psychiatry 42:1203-1211.

Gillis JJ, Gilger JW, Pennington BF, DeFries JC. 1992. Attention deficit disorder in reading-disabled twins: Evidence for a genetic etiology. J Abnorm Child Psychol 20:303-315.

Gjone H, Stevenson J, Sundet JM. 1996. Genetic influence on parent reported attention-related problems in a Norwegian general population twin sample. J Am Acad Child Adolesc Psychiatry 35:588-596.

Goodman R. 1997. The Strengths and Difficulties Questionnaire: A research note. J Child Psychol Psychiatry 38:581586.

Goodman R, Stevenson J. 1989. A twin study of hyperactivity-ll. The aetiological role of genes, family relationships and perinatal adversity. J Child Psychol Psychiatry 30:691-709. 
Hebebrand J, Dempfle A, Saar K, Thiele H, Herpertz-Dahlmann B, Linder $M$, Kiefl $H$, Remschmidt $H$, Hemminger $U$, Warnke $A$, Knolker $U$, Heiser $P$, Friedel $S$, Hinney A, Schafer $H$, Nurnberg $P$, Konrad K. 2006. A genome-wide scan for attention-deficit/hyperactivity disorder in 155 German sib-pairs. Mol Psychiatry 11(2):196-205.

Hudziak JJ, van Beijsterveldt CE, Bartels $M$, Rietveld MJ, Rettew DC, Derks EM, Boomsma DI. 2003. Individual differences in aggression: Genetic analyses by age, gender, and informant in 3-, 7-, and 10-year-old Dutch twins. Behav Genet 33:575-589.

Kuntsi J, Stevenson J. 2001. Psychological mechanisms in hyperactivity: II. The role of genetic factors. J Child Psychol Psychiatry 42:211-219.

Levy F, Hay DA, McStephen M, Wood C, Waldman I. 1997. Attention-deficit hyperactivity disorder: A category or a continuum? Genetic analysis of a largescale twin study. J Am Acad Child Adolesc Psychiatry 36:737-744.

Li D, Sham PC, Owen MJ, He L. 2006. Meta-analysis shows significant association between dopamine system genes and attention deficit hyperactivity disorder (ADHD). Hum Mol Genet 15(14):2276-2284.

Lowe N, Kirley A, Hawi Z, Sham P, Wickham $H$, Kratochvil CJ, Smith SD, Lee SY, Levy F, Kent L, Middle F, Rohde LA, Roman T, Tahir E, Yazgan $Y$, Asherson P, Mill J, Thapar A, Payton A, Todd RD, Stephens $T$, Ebstein RP, Manor I, Barr CL, Wigg KG, Sinke RJ, Buitelaar JK, Smalley SL, Nelson SF, Biederman J, Faraone SV, Gill M. 2004. Joint analysis of the DRD5 marker concludes association with attentiondeficit/hyperactivity disorder confined to the predominantly inattentive and combined subtypes. Am J Hum Genet
74:348-356.

Martin N, Scourfield J, McGuffin P. 2002. Observer effects and heritability of childhood attention-deficit hyperactivity disorder symptoms. $\mathrm{Br} J$ Psychiatry 180:260-265.

McArdle P, Prosser J, Kolvin I. 2004. Prevalence of psychiatric disorder: With and without psychosocial impairment. Eur Child Adolesc Psychiatry 136:347353.

Mill J, Xu X, Ronald A, Curran S, Price T, Knight J, Craig I, Sham P, Plomin R, Asherson P. 2005. Quantitative trait locus analysis of candidate gene alleles associated with attention deficit hyperactivity disorder (ADHD) in five genes: DRD4, DAT1, DRD5, SNAP-25, and 5HT1B. Am J Med Genet Part B 133B (1):68-73.

Mood AM, Graybill FA, Boes DC. 1974. Introduction to the theory of statistics. New York: McGraw Hill.

Nadder TS, Silberg JL, Eaves L, Maes HH, Meyer JM. 1998. Genetic effects on ADHD symptomatology in 7- to 13year-old twins: Results from a telephone survey. Behav Genet 28:8399.

Nadder TS, Rutter M, Silberg JL, Maes HH, Eaves LJ. 2002. Genetic effects on the variation and co-variation of attention deficit-hyperactivity disorder ADHD and oppositional-defiant disorder/conduct disorder ODD/CD symptomatologies across informant and occasion of measurement. Psychol Med 321:39-53. Erratum in: Psychol Med 32:378.

Ogdie MN, MacPhie IL, Minassian SL, Yang M, Fisher SE, Francks C, Cantor RM, McCracken JT, McGough JJ, Nelson SF, Monaco AP, Smalley SL. 2003.Agenomewide scan for attentiondeficit/hyperactivity disorder in an extended sample: Suggestive linkage on 
17p11.Am J Hum Genet 72:1268-1279.

Ogdie MN, Fisher SE, Yang $M$, Ishii J, Francks C, Loo SK, Cantor RM, McCracken JT, McGough JJ, Smalley SL, Nelson SF. 2004. Attention deficit hyperactivity disorder: Fine mapping supports linkage to $5 p 13,6 q 12,16 p 13$, and 17p11. Am J Hum Genet 75:661668.

Ogdie MN, Bakker SC, Fisher SE, Francks C, Yang $\mathrm{MH}$, Cantor RM, Loo SK, van der Meulen E, Pearson P, Buitelaar J, Monaco A, Nelson SF, Sinke RJ, Smalley SL. 2006. Pooled genome-wide linkage data on 424 ADHD ASPs suggests genetic heterogeneity and a common risk locus at $5 \mathrm{p} 13$. Mol Psychiatry 11(1):5-8.

Price TS, Simonoff E, Waldman I, Asherson P, Plomin R. 2001. Hyperactivity in preschool children is highly heritable. J Am Acad Child Adolesc Psychiatry 4:1362-1364.

Purcell S, Sham P. 2003. A model-fitting implementation of the DeFries-Fulker model for selected twin data. Behav Genet 33:271-278.

Rasmussen ER, Neuman RJ, Heath AC, Levy F, Hay DA, Todd RD. 2004. Familial clustering of latent class and DSM-IV defined attention-deficit/hyperactivity disorder (ADHD) subtypes. J Child Psychol Psychiatry 45(3):589-598.

Rietveld MJ, Hudziak JJ, Bartels M, van Beijsterveldt CE, Boomsma DI. 2003. Heritability of attention problems in children: I. Cross-sectional Results from a study of twins, age 3 to 12 years. Am J Med Genet 117B:102-113.

Rogers WH. 1993. Regression standard errors in clustered samples. Stata Tech Bull 13:19-23. Reprinted in Stata Technical Bulletin Reprints vol. 3, 8894.

Rothenberger A, Woerner W. 2004.
Strengths and Difficulties Questionnaire (SDQ)-Evaluations and applications. Eur Child Adolesc Psychiatry 13 (Suppl 2): 111-112.

Sham P. 2002. Recent Developments in Quantitative Trait Loci Analysis. In: Plomin R, DeFries JC, Craig IW, McGuffin $P$, editors. Behavioural genetics in the postgenomic era, $1 \mathrm{e}$. Washington DC: American Psychological Association. pp 41-54.

Sherman DK, McGue MK, lacono WG. 1997a. Twin concordance for attention deficit hyperactivity disorder: A comparison of teachers' and mothers' reports. Am J Psychiatry 154:532-535.

Sherman DK, lacono WG, McGue MK. 1997b. Attention-deficit hyperactivity disorder dimensions: A twin study of inattention and impulsivityhyperactivity. J Am Acad Child Adolesc Psychiatry 366:745-753.

Simonoff E, Pickles A, Hervas A, Silberg JL, Rutter M, Eaves L. 1998. Genetic influences on childhood hyperactivity: Contrast effects imply parental rating bias, not sibling interaction. Psychol Med 28: 825-837.

STATA 8. 2003. Base Reference Manual. Texas: Stata Press.

Stevenson J. 1992. Evidence for a genetic etiology in hyperactivity in children. Behav Genet 22:337-344.

Stevenson J, Asherson P, Hay D, Levy F, Swanson J, Thapar A, Willcutt E. 2005. Characterizing the ADHD phenotype for genetic studies developmental. Science $8(2): 115-121$.

Taylor E, Schachar R, Thorley G, Wieselberg M. 1986a. Conduct disorder and hyperactivity: I. Separation of hyperactivity and antisocial conduct in British child psychiatric patients. Br J Psychiatry 149:760-777.

Taylor E, Everitt B, Thorley G, Schachar R, 
Rutter M, Wieselberg M. 1986b. Conduct disorder and hyperactivity: II. A cluster analytic approach to the identification of a behavioral syndrome. Br J Psychiatry 149:768-777.

Taylor E, Schachar R, Thorley G, Wieselberg HM, Everitt B, Rutter $M$. 1987. Which boys respond to stimulant medication? A controlled trial of methylphenidate in boys with disruptive behavior. Psychol Med 17:121-143.

Taylor E, Chadwick O, Heptinstall E, Danckaerts M. 1996. Hyperactivity and conduct problems as risk factors for adolescent development. J Am Acad Child Adolesc Psychiatry 35:1213-1226.

Thapar A, Hervas A, McGuffin P. 1995. Childhood hyperactivity scores are highly heritable and show sibling competition effects: Twin study evidence. Behav Genet 25:537-544.

Thapar A, Holmes J, Poulton K, Harrington R. 1999. Genetic basis of attention deficit and hyperactivity. Br J Psychiatry 174:105-111.

Thapar A, Harrington R, Ross K, McGuffin P. 2000. Does the definition of ADHD affect heritability? J Am Acad Child Adolesc Psychiatry 39:1528-1536.

Thapar A, Fowler T, Rice F, Scourfield J, van den Bree $M$, Thomas $H$, Harold $G$, Hay D. 2003. Maternal smoking during pregnancy and attention deficit hyperactivity disorder symptoms in offspring. Am J Psychiatry 160(11): 1985-1989.

Thapar A, Langley K, O'Donovan M, Owen M. 2006. Refining the attention deficit hyperactivity disorder phenotype for molecular genetic studies. Mol Psychiatry 11(8):714-720.

Todd RD, Rasmussen ER, Neuman RJ, Reich W, Hudziak JJ, Bucholz KK, Madden PA, Heath A. 2001. Familiality and heritability of subtypes of attention deficit hyperactivity disorder in a population sample of adolescent female twins. Am J Psychiatry 158: 1891-1898.

Wallander JL. 1988. The relationship between attention problems in childhood and antisocial behavior eight years later. J Child Psychol Psychiatry 291:53-61.

Wechsler D. 1991.Wechsler Intelligence Scale for Children. 3rd edition. UK.

London: The Psychological Corporation.

Willcutt E. in press. The etiology of ADHD: Behavioral and molecular genetic approaches. In: Barch D, editor. Cognitive and affective neuroscience of psychopathology. New York: Oxford University Press.

Willcutt EG, Pennington BF, DeFries JC. 2000. Etiology of inattention and hyperactivity/impulsivity in a community sample of twins with learning difficulties. J Abnorm Child Psychol 28(2):149-159.

Willcutt EG, Pennington BF, Boada R, Ogline JS, Tunick RA, Chhabildas NA, Olson RK. 2001. A comparison of the cognitive deficits in reading disability and attention-deficit/hyperactivity disorder. J Abnorm Psychol 110:157172.

Williams RL. 2000. A note on robust variance estimation for cluster correlated data. Biometrics 56:645-64 